\title{
Intraoperative ventilator settings and acute lung injury after elective surgery: a nested case control study
}

\author{
E R Fernández-Pérez, ${ }^{1,6} \mathrm{~J}$ Sprung, ${ }^{3}$ B Afessa, ${ }^{2,6}$ D 0 Warner, ${ }^{3}$ C M Vachon, ${ }^{4}$ \\ D R Schroeder, ${ }^{5}$ D R Brown, ${ }^{3}$ R D Hubmayr, ${ }^{2,6}$ O Gajic ${ }^{2,6}$
}

- Additional methods and results are published online only at http://thorax.bmj.com/ content/vol64/issue2

${ }^{1}$ Division of Pulmonary and Critical Care Medicine, Department of Internal Medicine, National Jewish Health, Denver, Colorado, USA;

${ }^{2}$ Division of Pulmonary and Critical Care Medicine, Department of Interna Medicine, Mayo Clinic Rochester, Minnesota, USA

${ }^{3}$ Department of Anesthesiology, Mayo Clinic College of Medicine, Rochester, Minnesota, USA;

${ }^{4}$ Division of Epidemiology, Department of Health Sciences Research, Mayo Clinic College of Medicine, Rochester, Minnesota, USA; ${ }^{5}$ Division of Biostatistics, Department of Health Sciences Research,

Mayo Clinic College of Medicine, Rochester, Minnesota, USA;

${ }^{6}$ Mayo Epidemiology and

Translational Research in the Intensive Care (METRIC)

Correspondence to:

Dr E R Fernández-Pérez, National Jewish Health, 1400 Jackson

Street, G10a, Denver, CO

80206, USA; FernandezEvans@ njc.org

An abstract of this study was presented at the Society of Critical Care Medicine's 37th Critical Care Congress, 2-6

February 2008, Honolulu,

Hawaii, USA.

Received 9 June 2008 Accepted 7 September 2008

Published Online First

6 November 2008

\section{ABSTRACT}

Background: While acute lung injury (ALI) is among the most serious postoperative pulmonary complications, its incidence, risk factors and outcome have not been prospectively studied.

Objective: To determine the incidence and survival of ALI associated postoperative respiratory failure and its association with intraoperative ventilator settings, specifically tidal volume.

Design: Prospective, nested, case control study.

Setting: Single tertiary referral centre

Patients: 4420 consecutive patients without ALI undergoing high risk elective surgeries for postoperative pulmonary complications.

Measurements: Incidence of ALI, survival and 2:1 matched case control comparison of intraoperative exposures.

Results: 238 (5.4\%) patients developed postoperative respiratory failure. Causes included ALI in $83(35 \%)$, hydrostatic pulmonary oedema in $74(31 \%)$, shock in 27 $(11.3 \%)$, pneumonia in nine $(4 \%)$, carbon dioxide retention in eight (3.4\%) and miscellaneous in $37(15 \%)$. Compared with match controls $(n=166)$, ALI cases had lower 60 day and 1 year survival $(99 \%$ vs $73 \%$ and $92 \%$ vs $56 \% ; p<0.001)$. Cases were more likely to have a history of smoking, chronic obstructive pulmonary disease and diabetes, and to be exposed to longer duration of surgery, intraoperative hypotension and larger amount of fluid and transfusions. After adjustment for non-ventilator parameters, mean first hour peak airway pressure $(\mathrm{OR}$ 1.07: $95 \% \mathrm{Cl} 1.02$ to $1.15 \mathrm{~cm} \mathrm{H}_{2} \mathrm{O}$ ) but not tidal volume (OR 1.03; $95 \% \mathrm{Cl} 0.84$ to $1.26 \mathrm{ml} / \mathrm{kg}$ ), positive end expiratory pressure (OR $0.89 ; 95 \% \mathrm{Cl} 0.77$ to $1.04 \mathrm{~cm} \mathrm{H}_{2} \mathrm{O}$ ) or fraction of inspired oxygen (OR 1.0; $95 \% \mathrm{Cl} 0.98$ to 1.03 ) were associated with ALI.

Conclusion: ALl is the most common cause of postoperative respiratory failure and is associated with markedly lower postoperative survival. Intraoperative tidal volume was not associated with an increased risk for early postoperative ALI.

Postoperative pulmonary complications, and in particular postoperative respiratory failure, are important causes of perioperative morbidity and mortality. ${ }^{1-3}$ Of all the potential causes of early postoperative respiratory failure, acute lung injury $(\mathrm{ALI})^{4}$ may be the most serious, with estimated mortality rates exceeding $45 \%$ in some populations. ${ }^{56}$ The incidence, risk of intraoperative ventilator settings (specifically tidal volume) and attributable outcome of postoperative ALI have not been prospectively studied in large samples of patients undergoing elective surgery.

While ventilation induced lung injury contributes to ALI development and progression in patients undergoing mechanical ventilation in the intensive care unit, the role of short term intraoperative ventilation is less well defined. Two prior studies have identified mechanical ventilation with large intraoperative tidal volume or airway pressure $e^{8}$ to be associated with an increased risk of postoperative respiratory failure and ALI after lung resection. Several small randomised controlled trials have reported conflicting results regarding the influence of ventilator settings on surrogate end points of pulmonary and systemic inflammation..$^{9-16}$ Interpretation of these studies is limited by small sample size and measurement of surrogate markers instead of clinically significant outcomes.

The objective of this study was to estimate the incidence, risk of intraoperative ventilator settings (specifically tidal volume) and survival of ALI associated postoperative respiratory failure in patients undergoing elective surgery. We hypothesised that potentially injurious intraoperative ventilator settings (ie, higher tidal volumes) would be associated with higher risk of postoperative respiratory failure secondary to ALI.

\section{METHODS \\ Design}

Additional methods are provided in the online data supplement. We established an observational cohort of consecutive patients undergoing elective surgery at the Mayo Clinic, Rochester, Minnesota, USA, from November 2005 to August 2006 and documented the development of pulmonary complications over the first 5 postoperative days. We chose a 5 day follow-up period as respiratory failure directly attributable to interventions at the time of surgery is unlikely to occur later than 5 days after surgery. ${ }^{8}$ Using this cohort, we conducted a nested case control study with cases defined as those who developed ALI associated postoperative respiratory failure during the 5 days after surgical intervention and matched controls not developing postoperative pulmonary complications or respiratory failure over this time frame. Each case was matched to two controls selected at random from the pool of all potential controls matched for age (within 5 years), gender, American Society of Anesthesiologists' class ${ }^{17}$ and type of elective surgical intervention (by primary 
Table 1 Definitions of postoperative pulmonary complications

\begin{tabular}{|c|c|}
\hline Complication & Description \\
\hline Postoperative respiratory failure & $\begin{array}{l}\text { Need for mechanical ventilation for greater than } 48 \mathrm{~h} \text { postoperatively or the need for } \\
\text { reinstitution of mechanical or non-invasive ventilation after extubation. }\end{array}$ \\
\hline Acute lung injury & $\begin{array}{l}\text { (1) New or worsening hypoxaemia with a ratio of arterial oxygen to fraction of inspired } \\
\text { oxygen } \leqslant 300 \mathrm{~mm} \mathrm{Hg} \text { (ARDS }<200 \mathrm{~mm} \mathrm{Hg} \text { ) on } 2 \text { consecutive days, (2) new bilateral } \\
\text { pulmonary infiltrates on } 2 \text { consecutive days, (3) no evidence of left atrial hypertension } \\
\text { (pulmonary capillary wedge pressure } \leqslant 18 \mathrm{~mm} \mathrm{Hg} \text {, when available). }{ }^{4} \text { The diagnosis of } \\
\text { ALI or ARDS was mandatory to persist for more than } 24 \mathrm{~h} \text {. }\end{array}$ \\
\hline Hydrostatic pulmonary oedema & $\begin{array}{l}\text { Radiographic (diffuse bilateral pulmonary infiltrates), haemodynamic (pulmonary artery } \\
\text { occlusion pressure }>18 \mathrm{~mm} \mathrm{Hg} \text { or echocardiographic evidence of left ventricular or } \\
\text { right ventricular dysfunction and elevated ventricular filling pressures), laboratory (brain } \\
\text { natriuretic peptide }>350 \mathrm{pg} / \mathrm{ml} \text { ) and documented physical findings (gallop, jugular } \\
\text { venous distension). }\end{array}$ \\
\hline \multirow[t]{2}{*}{ Pneumonia } & $\begin{array}{l}\text { (a) New or progressive pulmonary infiltrate or consolidation in the chest radiograph and } \\
\text { one or more of the following: new onset of purulent sputum or change in the character } \\
\text { of sputum, sputum cultures showing a respiratory pathogen, isolation of pathogen from } \\
\text { specimen obtained by transtracheal aspirate or bronchial brushing/lavage. }\end{array}$ \\
\hline & $\begin{array}{l}\text { (b) Three or more of the following: fever (temperature }>101^{\circ} \mathrm{F}\left(38.5^{\circ} \mathrm{C}\right) \text { ), rales or } \\
\text { rhonchi on chest auscultation, new onset of purulent sputum or change in the character } \\
\text { of sputum, sputum cultures showing a respiratory pathogen, isolation of pathogen from } \\
\text { specimen obtained by transtracheal aspirate or bronchial brushing/lavage. }\end{array}$ \\
\hline Atelectasis & $\begin{array}{l}\text { Lobar or multilobar atelectasis on chest radiograph and requiring bronchoscopic } \\
\text { intervention. }\end{array}$ \\
\hline Pneumothorax & If newly present on chest radiograph and requiring chest tube placement. \\
\hline
\end{tabular}

$\mathrm{ALI}$, acute lung injury; ARDS, adult respiratory distress syndrome.

International Classification of Diseases, 9th revision, codes). For all cases and controls, we also evaluated length of stay, and 60 day and 1 year survival.

\section{Settings and participants}

Patients were included if mechanically ventilated for $\geqslant 3 \mathrm{~h}$ during general anaesthesia for the following procedures: (1) all cardiac and vascular surgeries, (2) non-cardiac thoracic surgeries, including oesophageal and pulmonary surgeries, (3) all major open abdominal surgeries, including laparoscopic procedures (excluding appendectomies and other lower abdominal procedures such as hernia repairs) and laparoscopic gastric bypasses, (4) non-orthopaedic spine surgeries, (5) surgical procedures on the hips and knees, (6) cystectomies, (7) neurosurgical procedures (excluding ventriculoperitoneal shunts, stereotactic and peripheral nerve surgeries) and (8) head and neck surgeries.

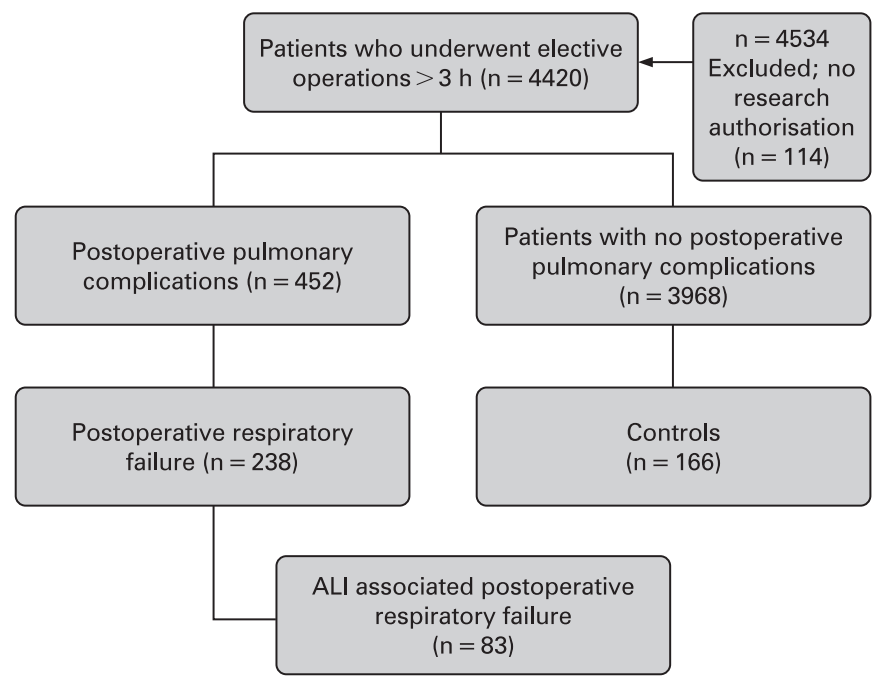

Figure 1 Flow diagram of study participants. ALI, acute lung injury.
Patients were excluded if: previously denied permission to utilise their health information for research, less than 18 years old, had prevalent risk factors for lung injury, respiratory failure or previously required mechanical ventilation: (1) mechanically ventilated prior to surgery, (2) had history of preoperative trauma, sepsis, aspiration, shock, acute congestive heart failure, idiopathic interstitial pneumonias, ${ }^{18}$ pneumonia or respiratory failure, (3) underwent emergency surgery, (4) had previous high risk surgery for postoperative pulmonary complications, ${ }^{1}{ }^{1}(5)$ had history of sleep apnoea or neuromuscular disease requiring continuous positive airway pressure for postoperative respiratory failure or (6) required re-intubation or need for mechanical ventilation for re-operation.

The Mayo Clinic Institutional Review Board approved the study.

\section{Measurements and outcomes}

One research coordinator (blinded to the assessment of outcomes) screened eligible patients daily from the institutional electronic surgical listing prior to surgical intervention and prospectively reviewed the medical records, and laboratory and radiology data. Information was abstracted on type and date of surgery, demographics, history of smoking and alcohol intake, presence or absence of comorbid conditions (diabetes mellitus, heart failure, hypertension, coronary artery disease, immunosuppression, chronic hepatic insufficiency and chronic renal insufficiency) height, weight and American Society of Anesthesiologists' class.

The following intraoperative data were abstracted from an electronic anaesthesia record: (1) oxygen saturation by pulse oximetry, (2) invasive haemodynamic parameters (systolic, diastolic and mean arterial blood pressures), (3) ventilator parameters (one vs two lung ventilation, ventilator mode, set respiratory rate, fraction of inspired oxygen $\left(\mathrm{FiO}_{2}\right)$, positive end expiratory pressure (PEEP), peak airway pressure and set tidal volume (ml/kg predicted body weight)), (4) quantity of blood product transfusions (red blood cells, platelets, fresh frozen plasma or cryoprecipitate), fluid balance (calculated as the 
Table 2 Postoperative pulmonary complications (with and without respiratory failure) by type of surgery

\begin{tabular}{lccclll}
\hline Type of surgery & $\mathbf{n}$ & $\begin{array}{l}\text { Hydrostatic oedema } \\
(\mathbf{n}(\%))\end{array}$ & $\begin{array}{l}\text { ALI } \\
(\mathbf{n}(\%))\end{array}$ & $\begin{array}{l}\text { Pneumonia } \\
(\mathbf{n}(\%))\end{array}$ & $\begin{array}{l}\text { Atelectasis } \\
(\mathbf{n}(\%))\end{array}$ & $\begin{array}{l}\text { Pneumothorax } \\
(\mathbf{n}(\%))\end{array}$ \\
\hline Cardiac & 1381 & $147(10.6)$ & $79(5.7)$ & $38(2.7)$ & $11(0.8)$ & $8(0.6)$ \\
Thoracic & 659 & $14(2)$ & $24(3.6)$ & $14(2)$ & $6(0.9)$ & $3(0.4)$ \\
Open abdomen & 547 & $7(1.2)$ & $8(1.5)$ & $2(0.4)$ & $1(0.2)$ & $2(0.4)$ \\
Orthopaedic & 399 & $12(3)$ & $4(1)$ & $1(0.2)$ & $1(0.2)$ & $1(0.2)$ \\
Peripheral vascular & 352 & $4(1)$ & $2(0.6)$ & $1(0.3)$ & 0 & 0 \\
Neurological & 339 & $2(0.6)$ & $3(0.9)$ & $2(0.6)$ & 0 & 0 \\
Non-orthopaedic spine & 258 & $2(0.8)$ & 0 & 0 & 1 & 0 \\
Aortic vascular & 148 & $23(15)$ & $11(7.4)$ & $6(4)$ & 0 & 0 \\
Laparoscopic abdominal & 123 & $2(1.6)$ & $1(0.8)$ & $1(0.8)$ & $1(0.8)$ & 0 \\
Urological & 158 & $3(1.8)$ & 0 & 0 & 0 & 0 \\
Head and neck & 24 & $1(4)$ & $1(4)$ & $2(8)$ & 0 & 0 \\
General & 33 & 0 & 0 & 0 & 0 & 0 \\
Total (\%) & 4420 & $217(4.9)$ & $133(3)$ & $67(1.5)$ & $21(0.5)$ & $14(0.3)$ \\
\hline
\end{tabular}

ALI, acute lung injury.

difference between the fluid intake and output during anaesthesia and (5) anaesthesia time. All intraoperative measurements were collected every $2 \mathrm{~min}$. The first and last $15 \mathrm{~min}$ of all ventilator variables were excluded from the analysis due to variability during induction and emergence. Ventilator settings during the first hour (primary predictor variable) and during the total time of anaesthesia were used. The first continuous hour of mechanical ventilation (after the initial $15 \mathrm{~min}$ ) were primarily utilised, as ventilator settings during the total time of anaesthesia are more likely to reflect an effect-cause relationship (eg, a patient who has worsening oxygenation may require higher tidal volumes and/or may have reduced respiratory system compliance with resultant high peak airway pressures from direct surgical interventions or pulmonary oedema from ongoing fluid administration). Of note, volume controlled ventilation was the primary mode of ventilation in all patients. One lung ventilation was started after the first hour in 28 patients. We were unable to use static compliance of the total respiratory system and a set flow rate and profile during the analysis as this was not routinely measured during intraoperative ventilation.

Postoperatively, a second investigator (blinded to the perioperative predictors) collected data on the occurrence of the primary outcome measure. Table 1 describes the outcome variables.

\section{Statistical analyses}

Based on our preliminary study of tidal volume as a risk factor for postoperative respiratory failure ${ }^{7}$ and taking the matched design into account, sample size calculations showed that approximately 70 ALI associated postoperative respiratory failure cases would provide a $90 \%$ statistical power (two tailed alpha $=0.05$ ) to detect a mean tidal volume difference of $1 \mathrm{ml} /$ $\mathrm{kg}$ predicted body weight between cases and controls. To account for subjects with potential missing data during the study, 18\% more patients were added (arbitrary estimation) for a final sample size of 83 patients.

Potential risk factors for ALI associated postoperative respiratory failure were evaluated using conditional logistic regression, making use of the 2:1 matched set study design. Univariate analyses were performed to assess each variable individually as a potential risk factor for ALI associated postoperative respiratory failure (see tables 4 and 5). For each ventilator variable (see table 6), additional multivariable analyses were performed to assess whether these variables were related to ALI associated postoperative respiratory failure after adjusting for non-ventilator characteristics.

Survival curves were constructed using the Kaplan-Meier methods and compared using the log rank test. In all cases, two sided tests were used, with $p$ values $\leqslant 0.05$ considered statistically significant.

Table 3 Postoperative respiratory failure intervention (within 5 days) by type of surgery

\begin{tabular}{lcccc}
\hline Type of surgery & $\mathbf{n}$ & $\begin{array}{l}\text { Mechanical } \\
\text { ventilation } \\
>\mathbf{4 8} \mathbf{~ h}\end{array}$ & Re-intubation & $\begin{array}{l}\text { Non-invasive } \\
\text { positive pressure } \\
\text { ventilation }\end{array}$ \\
\hline Cardiac & 1381 & 70 & 8 & 57 \\
Thoracic & 659 & 1 & 9 & 8 \\
Open abdomen & 547 & 7 & 3 & 10 \\
Orthopaedic & 399 & 9 & 3 & 6 \\
Peripheral vascular & 352 & 2 & 1 & 5 \\
Neurological & 339 & 4 & 0 & 2 \\
Non-orthopaedic spine & 258 & 4 & 0 & 1 \\
Aortic vascular & 148 & 13 & 1 & 5 \\
Laparoscopic abdominal & 123 & 1 & 0 & 4 \\
Urological & 158 & 0 & 0 & 0 \\
Neck & 24 & 3 & 0 & 0 \\
General & 33 & 0 & 1 & 0 \\
Total (\%) & 4420 & $114(2.6)$ & $26(0.6)$ & 98 (2.2) \\
\hline
\end{tabular}


Table 4 Univariate analysis of preoperative predictor variables of matched ALI case controls

\begin{tabular}{lcclc}
\hline Variable & $\begin{array}{l}\text { Controls }(\mathbf{n}=\mathbf{1 6 6}) \\
(\mathbf{n}(\%))\end{array}$ & $\begin{array}{l}\text { Cases }(\mathbf{n}=\mathbf{8 3}) \\
(\mathbf{n}(\%))\end{array}$ & OR (95\% Cl) & p Value \\
\hline Diabetes mellitus & $30(18.1)$ & $30(36.1)$ & $2.598(1.40-4.81)$ & 0.002 \\
Hypertension & $109(65.7)$ & $63(75.9)$ & $1.771(0.93-3.38)$ & 0.082 \\
Coronary artery disease & $97(58.4)$ & $53(63.9)$ & $1.371(0.72-2.61)$ & 0.339 \\
Heart failure & $60(36.1)$ & $24(28.9)$ & $0.651(0.34-1.25)$ & 0.198 \\
Immunosuppression & $2(1.2)$ & $4(4.8)$ & $6.606(0.72-60.86)$ & 0.096 \\
Chronic renal failure & $4(2.4)$ & $2(2.4)$ & & \\
Hepatic insufficiency & $2(1.2)$ & $2(2.4)$ & $2.000(0.28-14.19)$ & 0.488 \\
Asthma & $10(6.0)$ & $8(9.6)$ & $1.600(0.63-4.05)$ & 0.322 \\
COPD & $14(8.4)$ & $15(18.1)$ & $2.689(1.15-6.31)$ & 0.023 \\
Smoking & $83(50)$ & $56(70)$ & $2.43(1.31-4.51)$ & 0.005 \\
Alcohol & $40(24)$ & $28(35)$ & $1.86(1.00-3.50)$ & 0.055 \\
\hline
\end{tabular}

$\mathrm{ALI}$, acute lung injury; $\mathrm{COPD}$, chronic obstructive pulmonary disease.

\section{RESULTS}

Excluding 114 patients who did not authorise the use of health information for research, 4420 patients were eligible for the study (see flow diagram in fig 1). A total of 452 patients (10.2\%) developed postoperative pulmonary complications (table 2). Of these, 133 (29\%) developed ALI, of whom 55 had acute respiratory distress syndrome. The type of operation influenced the frequency of ALI; it varied from a low of $0.8 \%$ for laparoscopic abdominal procedures to a high of $7.4 \%$ for aortic vascular surgery (table 2). Two hundred and thirty-eight patients (incidence $5.4 \%$, 95\% confidence interval (CI) $4.7 \%$ to $6.1 \%$ ) experienced postoperative respiratory failure (table 3 ). ALI was the most common cause of postoperative respiratory failure occurring in $83(34.9 \%$ ) patients (incidence 1.9\%, 95\% CI $1.5 \%$ to $2.3 \%$ ). None of the ALI associated respiratory failure cases $(n=83)$ had other identifiable non-surgical explanations for ALI (eg, aspiration, pneumonia, sepsis). Non-ALI associated causes of postoperative respiratory failure included hydrostatic pulmonary oedema in 74 (31.1\%), shock in 27 (11.3\%), pneumonia in nine $(3.8 \%)$, carbon dioxide retention in eight $(3.4 \%)$ and miscellaneous in 37 (15.5\%).

Univariate analysis revealed that a preoperative history of diabetes, smoking and alcohol use were significant risk factors for ALI associated postoperative respiratory failure (table 4). Intraoperative factors significant in univariate analysis for ALI (tables 5 and 6) included duration of anaesthesia, transfusion of red blood cells, transfusion of non-red blood cell products, colloid infusion, fluid balance, mean arterial blood pressure, and mean $\mathrm{FiO}_{2}$ and mean peak airway pressure over the first hour of anaesthesia. When adjusted for non-ventilator parameters, mean intraoperative peak airway pressure, but not tidal volume, PEEP, respiratory rate or $\mathrm{FiO}_{2}$, was related to ALI associated postoperative respiratory failure (table 6). The same results were obtained when ventilator variables were calculated as the mean of values measured over the total duration of anaesthesia (see table 1 in the online supplement).

Inhospital mortality of patients with ALI associated postoperative respiratory failure $(17 \%, 14$ of 83$)$ was significantly higher than that of patients without postoperative respiratory failure $(5 \%(8 / 155) ; p=0.004)$. The 60 day and 1 year survival (fig 2) of patients with ALI associated respiratory failure (cases, $\mathrm{n}=83$ ) was $73 \%$ and $56 \%$, respectively, in contrast with $99 \%$ and $92 \%$ for patients that did not have postoperative pulmonary complications (controls, $\mathrm{n}=166$ ). Compared with control patients, ALI cases had longer hospital lengths of stay (mean $17,95 \%$ CI 15 to 21 days vs $5,95 \%$ CI 4 to 6 days; $\mathrm{p}<0.001$ ).

\section{DISCUSSION}

The main findings of this study are: (1) ALI occurred in 3\% of high risk elective surgeries and was the most common cause of postoperative respiratory failure, (2) compared with matched controls, patients with ALI associated postoperative respiratory failure had markedly lower postoperative survival and longer length of hospital stay and (3) when adjusted for non-ventilator variables, intraoperative peak airway pressure, but not tidal volume, PEEP or $\mathrm{FiO}_{2}$, was associated with ALI associated postoperative respiratory failure.

Although the observed incidence and outcome of postoperative ALI come as no surprise to practicing intensivists, this relationship may not be widely appreciated among internists, anaesthesiologists and surgeons involved in the perioperative management. In fact, no previous prospective study formally evaluated the development and outcome of postoperative ALI in a large sample of patients undergoing high risk elective surgery for postoperative pulmonary complications. There are several limitations of existing studies addressing the

Table 5 Univariate analysis of intraoperative predictor variables of matched ALI case controls

\begin{tabular}{|c|c|c|c|c|}
\hline Variable & $\begin{array}{l}\text { Controls }(n=166) \\
\text { (mean (SD)) }\end{array}$ & $\begin{array}{l}\text { Cases }(n=83) \\
(\text { mean }(S D))\end{array}$ & OR $(95 \% \mathrm{Cl})$ & p Value \\
\hline Duration of anaesthesia (min) & $324(113)$ & $450(161)$ & $1.64 *(1.37-1.96)$ & $<0.001$ \\
\hline Non-red blood cells (ml) & $122(432)$ & $683(1161)$ & $1.13 \dagger(1.06-1.20)$ & $<0.001$ \\
\hline Red blood cells (ml) & $760(941)$ & 1723 (1939) & $1.06 \dagger(1.03-1.09)$ & $<0.001$ \\
\hline Colloids (ml) & $736(658)$ & $1101(832)$ & $1.07 \dagger(1.03-1.11)$ & $<0.001$ \\
\hline Fluid balance (I) & $3.69(2.21)$ & $6.1(3.77)$ & $1.03 \dagger(1.02-1.05)$ & $<0.001$ \\
\hline Blood pressure (mm Hg) & $71(7.64)$ & $67.9(8)$ & $0.93(0.89-0.97)$ & 0.001 \\
\hline $\mathrm{SpaO}_{2}(\%)$ & $98.5(2.06)$ & $98.6(1.38)$ & $0.63(0.89-1.03)$ & 1.212 \\
\hline
\end{tabular}

*Per hour; †per $100 \mathrm{ml}$.

\#Non-red blood cells: platelets, fresh frozen plasma or cryoprecipitate.

$\mathrm{ALI}$, acute lung injury; $\mathrm{SpaO}_{2}$, peripheral arterial haemoglobin oxygen saturation. 
Table 6 Unadjusted univariate and adjusted multivariate analysis of intraoperative ventilator variables of matched ALI case controls

\begin{tabular}{|c|c|c|c|c|c|c|}
\hline Variable & $\begin{array}{l}\text { Controls } \\
(n=166) \\
(\text { mean (SD)) }\end{array}$ & $\begin{array}{l}\text { Cases } \\
(\mathrm{n}=83) \\
(\text { mean (SD)) }\end{array}$ & $\begin{array}{l}\text { Unadjusted OR } \\
\text { (95\%Cl) }\end{array}$ & p Value & $\begin{array}{l}\text { Adjusted OR } \\
(95 \% \mathrm{Cl})^{*}\end{array}$ & p Value \\
\hline \multicolumn{7}{|l|}{ First hour } \\
\hline Tidal volume/kg PBW & $8.7(1.7)$ & $8.9(1.6)$ & $1.08(0.92-1.27)$ & 0.336 & $1.03(0.84-1.26)$ & 0.801 \\
\hline PEEP $\left(\mathrm{cm} \mathrm{H}_{2} \mathrm{O}\right)$ & $1.7(2.2)$ & $1.4(2.5)$ & $0.94(0.83-1.07)$ & 0.344 & $0.89(0.77-1.04)$ & 0.180 \\
\hline Peak airway pressure $\left(\mathrm{cm} \mathrm{H}_{2} \mathrm{O}\right)$ & $19(4.8)$ & $21(5.9)$ & $1.10(1.04-1.15)$ & $<0.001$ & $1.07(1.02-1.15)$ & 0.045 \\
\hline Respiratory rate (cycles/min) & $11(1.4)$ & $11(1.3)$ & $1.01(0.82-1.24)$ & 0.909 & $1.01(0.77-1.32)$ & 0.940 \\
\hline $\mathrm{FiO}_{2}(\%)$ & $73(18)$ & $80(17)$ & $1.03(1.01-1.04)$ & 0.002 & $1.00(0.98-1.03)$ & 0.708 \\
\hline
\end{tabular}

incidence and prognosis of postoperative ALI, including: (1) retrospective design, ${ }^{58}$ (2) inclusion of cases with prevalent risk factors for ALI, ${ }^{6}{ }^{19}$ (3) lack of a clear definition of postoperative ALI, ${ }^{21}{ }^{21}$ (4) restricted to specific age groups ${ }^{22}$ and (5) examination of only inhospital mortality as an endpoint. ${ }^{22} 23$ Furthermore, none of the published studies to date have provided an assessment of the relative contribution of ALI in determining postoperative respiratory failure and long term postoperative survival and we therefore cannot compare our findings with those of other studies. However, the 6 month survival of $63 \%$ (fig 2 ) in our study is similar to that found in the prospective study at the Mayo Clinic by Yilmaz et al in medical, surgical, and mixed medical-surgical ICU patients with ALI (62\%). ${ }^{24}$ Consistent with our findings, the importance of perioperative risk factors in determining the incidence of ALI after specific surgeries has been reported by others ${ }^{825}$ and may represent an attractive target for the prevention of postoperative ALI (eg, strategies to prevent intraoperative transfusion related ALI, perioperative antioxidants in those with a history of alcoholism). ${ }^{26-28}$

The development of ALI associated postoperative respiratory failure in our study was associated with markedly worse outcome compared with all other causes of postoperative respiratory failure combined and at 1 year compared with matched controls. This is a significant problem given the fact that over 40 million surgical procedures are performed in the USA annually ${ }^{29}$ with several million of these procedures representing high risk surgery for postoperative pulmonary complications. ${ }^{16}$ Thus identification of mechanisms contributing to the development of this complication and testing preventive interventions geared towards improved intraoperative care is needed to reduce the occurrence of postoperative ALI. One of the main aims of our study was to explore one of the potential mechanisms: ventilation induced lung injury and the relationship between intraoperative ventilator parameters and the development of postoperative ALI. We hypothesised that the use of high volume ventilation in patients in the operating room may initiate injury or conversely, that intraoperative protective ventilation can favourably influence outcome by attenuating the pulmonary and systemic inflammatory response. Nine small randomised controlled trials of patients with healthy lungs undergoing elective surgery evaluated the effect of protective versus conventional mechanical ventilation on several surrogate endpoints. ${ }^{9-16}$ In four studies, the concentration of proinflammatory cytokines did not differ between patients randomised to receive either high or
Figure 2 Survival of patients with acute lung injury associated respiratory failure compared with controls.

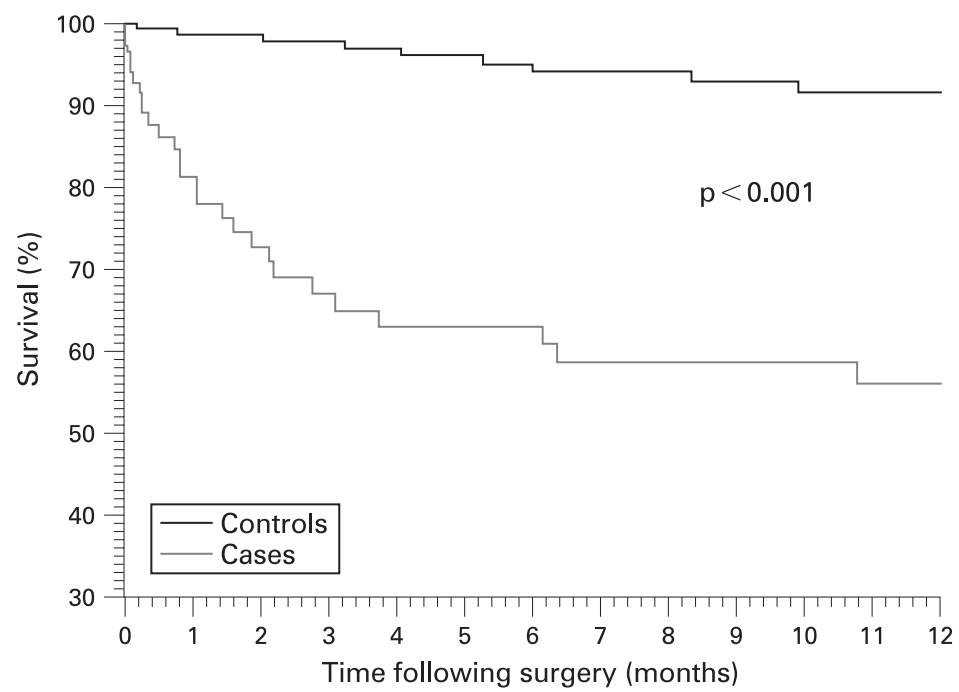

The number of patients at risk at each month:

\begin{tabular}{|l|rrrrrrrrrrrrr|}
\hline Month & 0 & 1 & 2 & 3 & 4 & 5 & 6 & 7 & 8 & 9 & 10 & 11 & 12 \\
\hline Case & 83 & 49 & 41 & 33 & 30 & 29 & 29 & 26 & 26 & 24 & 23 & 19 & 12 \\
\hline Control & 166 & 130 & 124 & 117 & 110 & 102 & 96 & 86 & 81 & 76 & 71 & 58 & 48 \\
\hline
\end{tabular}


low tidal volumes. In contrast, five other studies found that mechanical ventilation with larger tidal volumes and low PEEP was associated with pulmonary procoagulant changes, higher cytokine levels and postoperative pulmonary dysfunction (increases in airway pressure, decreases in lung compliance and increases in shunt) to a greater extent than that seen in patients ventilated with small tidal volumes and higher PEEP.

Exposure to higher peak airway pressure, but not tidal volume, was associated with the development of ALI in our study. A number of hypotheses could explain the observation that ALI associated postoperative respiratory failure is associated with higher intraoperative peak airway pressures compared with controls. High peak pressure suggests either systematic group differences in ventilator settings (eg, flow rate and profile) or systematic differences in the mechanical properties of the intubated respiratory system (eg, differences in respiratory system compliance and resistance, including effects of auto-PEEP). Given the small variability and lack of association between tidal volume and outcome, the differences in peak pressures may be explained by subtle differences in lung mechanics and thus function at baseline (ie, pre-existing lung disease, degree of post-intubation atelectasis) making these patients more susceptible to ventilator associated lung injury. Restricting the analysis to those with peak airway pressure $\geqslant 20 \mathrm{~mm} \mathrm{H}_{2} \mathrm{O}$ (controls $74(45.4 \%)$, cases $59(71.2 \%)$ ) the unadjusted odds ratio was 2.98 (95\% CI 1.67 to $5.34, p<0.001)$ but 1.68 (0.79 to $1.32, p=0.182)$ after adjustment. More evidence on this potential association is needed and we would not recommend any change in practice on the strength of this specific finding. On the other hand, intraoperative ventilation with modest tidal volumes ( $<9 \mathrm{ml} / \mathrm{kg}$ predicted body weight) as used in this study does not appear to increase the risk of postoperative ALI.

In the prospective cohort study of Esteban and colleagues, ${ }^{30}$ critically ill patients requiring mechanical ventilation for conditions not fulfilling acute respiratory distress syndrome criteria, mortality was associated with high peak $\left(>50 \mathrm{~cm} \mathrm{H}_{2} \mathrm{O}\right)$ and plateau pressure $\left(>35 \mathrm{~cm} \mathrm{H}_{2} \mathrm{O}\right)$. Three historical cohort studies also identified high airway pressures and tidal volumes as independent risk factors for development of ALI in patients requiring mechanical ventilation for acute respiratory failure. ${ }^{31-33}$ With a mean tidal volume of approximately $10 \mathrm{ml} / \mathrm{kg}$ of predicted body weight, the mean peak pressure in those who developed ALI from these three studies ranged between 32 and $35 \mathrm{~cm} \mathrm{H}_{2} \mathrm{O}$. Van der Werf and colleagues $^{34}$ studied 190 patients who underwent lung resection and found that peak inspiratory pressures in excess of $40 \mathrm{~cm} \mathrm{H} \mathrm{H}_{2} \mathrm{O}$ were associated with the development of postpneumonectomy pulmonary oedema (relative risk 3.0; 95\% CI 1.2 to 7.3). In the study by Licker and colleagues, ${ }^{8}$ of 879 patients undergoing lung resection for lung cancer, the "ventilatory hyperpressure index" (product of duration of one lung ventilation and inspiratory plateau pressure exceeding $10 \mathrm{~cm} \mathrm{H}_{2} \mathrm{O}$ ) was associated with the development of ALI in the postoperative period (OR 3.53; 95\% CI 1.71 to 8.45). Excessive airway pressures (mean plateau pressure of $29 \mathrm{~cm} \mathrm{H} \mathrm{H}_{2} \mathrm{O}$ ) were likely to have contributed to the development of ALI in these patients undergoing lung resection. On the other hand, it is less clear to what extent, if at all, the ventilation at mildly increased airway pressures (mean peak airway pressure of $21 \mathrm{~cm} \mathrm{H}_{2} \mathrm{O}$ ) contributed to the development of ALI in our study. Although controversy remains regarding the extent to which tidal volume and inspiratory airway pressures should be reduced to optimise clinical outcomes in patients with ALI and the best intraoperative ventilator thresholds in patients with normal lungs or at risk for ALI, trying to relate lung injury to a single ventilator variable is probably naive.

The strengths of this study include rigorous methods to minimise bias (concealed outcome ascertainment and data analysis, explicit definitions outlined a priori, collecting predictor variables before the outcome has occurred establishing a sequence of events, and random control sampling from a large concurrent cohort) and confounding (exclusion of prevalentincident cases, matching and multivariate adjustment). However, our study has several potential shortcomings. First of all, potential postsurgical differences such as in mechanical ventilation settings and fluid management could affect our results. Secondly, residual confounding caused by unmeasured variables (eg, surgical complications, intraoperative atelectasis) and absence of important ventilator variables such as static compliance limits the interpretation of our findings. Although we attempted to distinguish ALI from cardiogenic pulmonary oedema by utilising current accepted diagnostic criteria and relying on prospective screening, it is possible that some patients who presented with ALI had hydrostatic pulmonary oedema. Sensitivity and specificity of either clinical assessment or pulmonary artery occlusion pressure have not been rigorously defined and are likely modest at best. ${ }^{35}$ The specific cause of death for each patient was not recorded. Finally, our study took place in a single tertiary referral centre. However, patients at other referral and community centres in the country, undergoing these types of outlined elective surgeries, should not differ considerably from those enrolled in the study with regard to age, sex, severity of illness and comorbid conditions.

In conclusion, in this prospective cohort study, ALI was the most common cause of postoperative respiratory failure and was associated with markedly lower short and long term postoperative survival. Intraoperative ventilation with limited tidal volumes, as used in this study, does not appear to increase the risk of ALI associated postoperative respiratory failure.

Acknowledgements: The authors wish to acknowledge Lavonne Liedl and Gregory Wilson for assistance in data collection and Andrew Hanson for statistical advice and analysis

Funding: The study was supported by a Mayo foundation grant (CR20).

Competing interests: None.

Ethics approval: The Mayo Clinic Institutional Review Board approved the study

\section{REFERENCES}

1. Smetana GW, Lawrence VA, Cornell JE. Preoperative pulmonary risk stratification for noncardiothoracic surgery: systematic review for the American College of Physicians. Ann Intern Med 2006;144:581-95.

2. Arozullah AM, Daley J, Henderson WG, et al. Multifactorial risk index for predicting postoperative respiratory failure in men after major noncardiac surgery. The National Veterans Administration Surgical Quality Improvement Program. Ann Surg 2000;232:242-53.

3. Johnson RG, Arozullah AM, Neumayer L, et al. Multivariable predictors of postoperative respiratory failure after general and vascular surgery: results from the patient safety in surgery study. J Am Coll Surg 2007;204:1188-98.

4. Bernard GR, Artigas A, Brigham KL, et al. The American-European Consensus Conference on ARDS. Definitions, mechanisms, relevant outcomes, and clinical trial coordination. Am J Respir Crit Care Med 1994;149:818-24.

5. Ruffini E, Parola A, Papalia E, et al. Frequency and mortality of acute lung injury and acute respiratory distress syndrome after pulmonary resection for bronchogenic carcinoma. Eur J Cardiothorac Surg 2001;20:30-6.

6. Kutlu CA, Williams EA, Evans TW, et al. Acute lung injury and acute respiratory distress syndrome after pulmonary resection. Ann Thorac Surg 2000;69:376-80.

7. Fernandez-Perez ER, Keegan MT, Brown DR, et al. Intraoperative tidal volume as a risk factor for respiratory failure after pneumonectomy. Anesthesiology 2006;105:14-18.

8. Licker $\mathbf{M}$, de Perrot M, Spiliopoulos A, et al. Risk factors for acute lung injury after thoracic surgery for lung cancer. Anesth Analg 2003;97:1558-65. 
9. Michelet P, D'Journo XB, Roch A, et al. Protective ventilation influences systemic inflammation after esophagectomy: a randomized controlled study. Anesthesiology 2006;105:911-19.

10. Wrigge H, Uhlig U, Zinserling J, et al. The effects of different ventilatory settings on pulmonary and systemic inflammatory responses during major surgery. Anesth Analg 2004;98:775-81.

11. Wrigge H, Uhlig U, Baumgarten G, et al. Mechanical ventilation strategies and inflammatory responses to cardiac surgery: a prospective randomized clinical trial. Intensive Care Med 2005;31:1379-87.

12. Koner 0, Celebi S, Balci $\mathrm{H}$, et al. Effects of protective and conventional mechanical ventilation on pulmonary function and systemic cytokine release after cardiopulmonary bypass. Intensive Care Med 2004;30:620-6.

13. Choi G, Wolthuis EK, Bresser P, et al. Mechanical ventilation with lower tidal volumes and positive end-expiratory pressure prevents alveolar coagulation in patients without lung injury. Anesthesiology 2006;105:689-95.

14. Reis Miranda D, Gommers D, Struijs A, et al. Ventilation according to the open lung concept attenuates pulmonary inflammatory response in cardiac surgery. Eur J Cardiothorac Surg 2005;28:889-95.

15. Zupancich E, Paparella D, Turani F, et al. Mechanical ventilation affects inflammatory mediators in patients undergoing cardiopulmonary bypass for cardiac surgery: a randomized clinical trial. J Thorac Cardiovasc Surg 2005;130:378-83.

16. Wrigge H, Zinserling J, Stuber F, et al. Effects of mechanical ventilation on release of cytokines into systemic circulation in patients with normal pulmonary function. Anesthesiology 2000;93:1413-17.

17. Dripps RD, Lamont A, Eckenhoff JE. The role of anesthesia in surgical mortality. Jama 1961:178:261-6.

18. Demedts $\mathbf{M}$, Costabel U. ATS/ERS international multidisciplinary consensus classification of the idiopathic interstitial pneumonias. Eur Respir J 2002;19:794-6.

19. Algar FJ, Alvarez A, Salvatierra A, et al. Predicting pulmonary complications after pneumonectomy for lung cancer. Eur J Cardiothorac Surg 2003;23:201-8.

20. Mitchell CK, Smoger SH, Pfeifer MP, et al. Multivariate analysis of factors associated with postoperative pulmonary complications following general elective surgery. Arch Surg 1998;133:194-8.

21. Reilly DF, McNeely MJ, Doerner D, et al. Self-reported exercise tolerance and the risk of serious perioperative complications. Arch Intern Med 1999;159:2185-92.
22. Polanczyk CA, Marcantonio E, Goldman L, et al. Impact of age on perioperative complications and length of stay in patients undergoing noncardiac surgery. Ann Intern Med 2001;134:637-43.

23. Griffin SM, Shaw IH, Dresner SM. Early complications after Ivor Lewis subtotal esophagectomy with two-field lymphadenectomy: risk factors and management. J Am Coll Surg 2002;194:285-97.

24. Yilmaz M, Iscimen R, Keegan MT, et al. Six-month survival of patients with acute lung injury: prospective cohort study. Crit Care Med 2007;35:2303-7.

25. Tandon S, Batchelor A, Bullock R, et al. Peri-operative risk factors for acute lung injury after elective oesophagectomy. Br J Anaesth 2001;86:633-8.

26. Gajic 0, Rana R, Winters JL, et al. Transfusion-related acute lung injury in the critically ill: prospective nested case-control study. Am J Respir Crit Care Med 2007:176:886-91.

27. Koch CG, Li L, Sessler DI, et al. Duration of red-cell storage and complications after cardiac surgery. N Engl J Med 2008;358:1229-39.

28. Moss M, Bucher B, Moore FA, et al. The role of chronic alcohol abuse in the development of acute respiratory distress syndrome in adults. JAMA 1996;275:50-4.

29. Gottlieb S. United States brings in new rules to prevent surgical errors. BMJ 2004;329:13

30. Esteban A, Anzueto A, Frutos F, et al. Characteristics and outcomes in adult patients receiving mechanical ventilation: a 28-day international study. JAMA 2002; 287:345-55.

31. Gajic 0, Dara SI, Mendez JL, et al. Ventilator-associated lung injury in patients without acute lung injury at the onset of mechanical ventilation. Crit Care Med 2004;32:1817-24.

32. Gajic 0, Frutos-Vivar F, Esteban A, et al. Ventilator settings as a risk factor for acute respiratory distress syndrome in mechanically ventilated patients. Intensive Care Med 2005;31:922-6.

33. Jia MEX, Malhotra A, Saeed M, et al. Risk factors for acute respiratory distress syndrome in patients mechanically ventilated for greater than 48 hours. Chest 2008;133:853-61.

34. van der Werff YD, van der Houwen HK, Heijmans PJ, et al. Postpneumonectomy pulmonary edema. A retrospective analysis of incidence and possible risk factors. Chest 1997;111:1278-84.

35. Pinsky MR. Clinical significance of pulmonary artery occlusion pressure. Intensive Care Med 2003;29:175-8.

\section{Cystic fibrosis: a novel therapeutic angle or a false dawn}

Worldwide, approximately $10 \%$ of patients with cystic fibrosis have premature stop codons in the mRNA for the CFTR gene. These result in phenotypically severe variants of cystic fibrosis. PTC124 is a small molecule available as an oral preparation which allows the ribosome to selectively ignore these mutations and hence produce the functioning protein.

This prospective phase II trial recruited 23 adults with cystic fibrosis, all of whom had at least one nonsense mutation. The patients were given PTC124 orally in two cycles of 28 days. In the first cycle, $16 \mathrm{mg} / \mathrm{kg}$ was administered daily in three divided doses for 14 days followed by 14 days without treatment. In the second cycle, the same patients received an increased dose of $40 \mathrm{mg} / \mathrm{kg}$.

Across both cycles, statistical significance was achieved in the three primary outcome goals using nasal potential measurement. There were increases in total chloride transport, in the proportion who developed normal chloride transport and in the proportion of patients who responded to treatment predefined as a change in potential difference of $-5 \mathrm{mV}$ or more. No drug-related serious adverse events were recorded.

The results were less impressive in the second cycle. The authors attribute this to a possible decrease in sensitivity of nasal potential difference with repeated testing, but did not consider other causes such as a tolerability effect with PTC124 or a dose saturation below $40 \mathrm{mg} / \mathrm{kg}$. The numbers are small and judgement should be reserved until phase III trials are undertaken; however, these results are promising and may herald a trend towards individually tailored genetic treatment for specific mutations in cystic fibrosis.

- Kerem E, Hirawat S, Armoni S, et al. Effectiveness of PTC124 treatment of cystic fibrosis caused by nonsense mutations: a prospective phase II trial. Lancet 2008;372:719-27.

\section{P M George}

Correspondence to: Dr P M George, ST2, Respiratory Medicine, Royal Brompton Hospital, London, UK; petergeorge@doctors. org.uk 